\title{
Regímenes de Bienestar y gobiernos "progresistas" en América Latina: los casos de Venezuela, Ecuador y Bolivia
}

\author{
Analía Minteguiaga \\ Instituto de Investigaciones Gino GERMANI (UBA-CONICET-Argentina) \\ Instituto de Altos Estudios Nacionales (IAEN-Ecuador) \\ analiaminte@hotmail.com / analia.minteguiaga@iaen.edu.ec
}

Gemma UBASART-GonZÁLEZ

Universitat de Girona (España)

gemma.ubasart@udg.edu

Recibido: 27-05-2014

Aceptado: 01-10-2015

\section{Resumen}

Varios han sido los autores que, a partir de los trabajos de Esping-Andersen (1993, 2000), han aplicado el concepto de Régimen de Bienestar para estudiar las políticas sociales en América Latina. Entre otros, Martínez Franzoni (2007) elabora una tipología, con trabajo de campo que se sitúa en el cambio de milenio, y que establece tres categorías comparativas: regímenes Estatal-productivistas, Estatal-proteccionistas y familiaristas. La mayoría de países de la región son ubicados en la última categoría. La hipótesis del presente artículo plantea que con la irrupción de gobiernos considerados de "izquierda" o "progresistas" en varios países de la región a partir de fines de los '90 y, más decididamente, en el 2000, el mapa de los modelos de bienestar parece haber mutado de manera substantiva. Las experiencias transformadoras a nivel nacional son distintas, en razón de las diversas realidades económico-sociales y de acción política en las que se asientan, pero éstas poseen varios puntos de contacto pudiendo resumirse en una mayor intervención del Estado en diferentes ámbitos antes vedados a su accionar y en la recuperación de importantes funciones de bienestar y cuidado de la población por parte de los poderes públicos. El documento analiza de forma exploratoria y descriptiva las características principales de los Regímenes de Bienestar que se estarían configurando en tres países que han constitucionalizado el cambio de rumbo alejándose (en grados diferentes) del paradigma neoliberal — Venezuela, Bolivia y Ecuador-, y que muestran las dinámicas antes apuntadas.

Palabras clave: Régimen de Bienestar; política social; Ecuador; Bolivia; Venezuela; políticas públicas; transformaciones estatales. 


\title{
Welfare Regimes and "Progressive" Governments in Latin America: The Cases of Venezuela, Ecuador and Bolivia
}

\begin{abstract}
Several authors have applied the concept of Welfare Regimens for studying social policy in Latin America (Esping-Andersen, 1993 and 2000). Among others, Martínez Franzoni (2007) develops a typology, with field work is at the turn of the millennium, and establishes three categories: State-productivist regime, state-protectionist and family orientated. Most countries in the region are placed in the latter category. The hypothesis of this article argues that with the emergence of governments considered "left" or "progressive" in several countries of the region from the late '90s and, more decisively, in 2000', the map of welfare regimes models could have mutated substantively. The nationally transformative experiences are different (various socio-economic realities and political action in which they are located exists) but they have several contact points that can be summarized in a greater state intervention in different areas previously closed to their operating and recovery of important functions of welfare and care of the population by the government. The paper discusses with an exploratory and descriptive approach the welfare schemes that would shape in three countries that have constitutionalized the change from the neoliberal paradigm: Venezuela, Bolivia and Ecuador.
\end{abstract}

Keywords: Welfare Regimes; Social Policy; Ecuador; Bolivia; Venezuela; Public Policies; Statal Transformations.

\section{Referencia normalizada}

Minteguiaga, A. y G. Ubasart-González (2015): "Regímenes de Bienestar y gobiernos "progresistas" en América Latina: los casos de Venezuela, Ecuador y Bolivia", Política y Sociedad, 52 (3), pp. 691-718.

Sumario: 1. Introducción. 2. Regímenes de Bienestar: conceptos que innovan los análisis y las políticas. 3. Los casos de Ecuador, Venezuela y Bolivia. 4. A modo de conclusión. Entre la continuidad y el cambio. 5. Bibliografía. 


\section{Introducción}

Con el triunfo electoral en 1998 de Hugo Chávez en Venezuela se abre un periodo de cambio en América Latina'. Si bien cada experiencia nacional despliega sus propias especificidades, buena parte de éstas han asumido - al menos discursivamente- como objetivo "desmontar el núcleo duro de la agenda neoliberal y recuperar ciertas funciones de bienestar social y regulación económica, como se venía realizando aunque de modo muy desigual, en los años previos al ajuste estructural" (Ramírez, 2006: 33). Tales procesos han buscado revertir (con mayor o menor éxito) las condiciones materiales y simbólicas heredadas de la implementación durante más de dos décadas de políticas neoliberales derivadas del Consenso de Washington, las cuales se caracterizaron por promover la "flexibilización laboral, la privatización, la desregulación, la apertura de las cuentas comercial y financiera, la reducción del tamaño del Estado, etc.”(Falconí y Muñoz, 2012: 77); y que terminaron provocando, entre otros efectos, el aumento de la desigualdad y la pobreza, una (re)distribución regresiva del ingreso, así como la reproducción de una estructura productiva ociosa y rentista, enfocada más en los beneficios del comercio exterior de materias primas, que en la satisfacción de las necesidades del país.

Para comprender el proceso de cambio que están atravesando varios países de América Latina (de forma constitucionalizada en el caso de Bolivia, Ecuador y Venezuela) resulta importante analizar de manera específica el tipo de intervención estatal en el campo social, en los procesos de distribución y redistribución de recursos y en la provisión de cuidados y bienestares a la ciudadanía. Diversas publicaciones recogen los logros conseguidos durante el período en lo que tiene que ver con mejoras en reducción de la pobreza y la desigualdad, el aumento de la cobertura en servicios de salud y educación o aumento de la calidad del trabajo productivo — avances reconocidos también por organismos nacionales e internacionales-, aunque son pocos aún los análisis críticos que buscan comprender, de una manera multisectorial y estructural, las intervenciones que se están realizando a nivel del Régimen de Bienestar. Es fundamental, por tanto, identificar las dinámicas de continuidad y cambio que se producen en las agendas sociales en sentido amplio².

Además, hay que decir que los procesos de transformación señalados no sólo están introduciendo modificaciones substanciales en las políticas y organizaciones estatales en muchos países latinoamericanos, sino que también están provocando el surgimiento de nuevas preocupaciones intelectuales y académicas en la región. Así pues, parafra-

${ }^{1}$ Le siguen Brasil (2003, 2006, 2011), Argentina (2003, 2007 y 2011), Uruguay (2005, 2010), Bolivia (2006, 2010), Ecuador (2007, 2009 y 2013), Nicaragua (2007, 2012) y Paraguay (2008).

${ }^{2}$ Al menos los sectores de política analizados bajo la noción de Régimen de Bienestar abarcan las políticas de: educación, salud, seguridad social, de atención a la dependencia y grupos de atención prioritaria, tributaria y empleo. 
seando a Martínez Franzoni (2007:4), podemos decir que "las consideraciones redistributivas vuelven a la escena" del debate. Se modifican realidades y también esquemas analíticos. En este sentido, no es gratuito que se comience a hablar de sistemas nacionales de inclusión, de políticas integrales de salud o de educación, así como también que en el campo académico empiece a utilizarse el concepto de Regímenes de Bienestar, de cuño claramente europeo, que se consolidó a partir de las aportaciones realizadas por Gosta Esping-Andersen (1993, 2000).

De la misma manera que esta nueva agenda de investigación sobre esquemas de bienestar supuso un salto cualitativo en los trabajos que se venían haciendo en Europa sobre la evolución de los "Estados del Bienestar"3, surgidos inmediatamente después de la Segunda Guerra Mundial (II GM) — y en el caso del Sur europeo a partir de los 80’-, presenta, en tanto aproximación analítica, grandes potencialidades para la comprensión contemporánea de la recuperación de la función social que están viviendo muchos Estados de la región. Sin embargo, es indispensable aplicar una estrategia heterodoxa y no de simple importación acrítica de aquellos marcos analíticos. Las características propias de los esquemas de bienestar en los países latinoamericanos - con aún importantes niveles de informalidad y precariedad en el mercado de trabajo, instituciones estatales poco sólidas y un peso importante de la familia (y en concreto de la mujer) en la provisión de cuidados - obligan a pensar en la necesidad de aplicar perspectivas de análisis más abiertas y flexibles que las que nos ofrecían las aproximaciones clásicas en el campo de estudio de los Estados de Bienestar y las políticas sociales. Y algunos elementos de esta agenda inaugurada por Esping-Andersen son de utilidad.

Así pues, en el presente texto se pretende introducir algunas reflexiones teóricas y metodológicas que permitan consolidar una agenda de investigación con la finalidad de indagar sobre el tipo y las principales características de los Regímenes de Bienestar (que contemplan pero exceden a las políticas sociales) que se proyectan en los países en transformación en América Latina. A partir de un análisis bibliográfico, y de una primera aproximación a datos cuantitativos y cualitativos para comprender las modificaciones de los tres países de la región que constitucionalizaron el cambio, se trazarán algunas ideas sobre los modelos de bienestar en construcción. No se trata de un trabajo cerrado sino más bien preliminar y sensibilizador. La principal intención es la de abrir preguntas y dejar apuntados retos para futuras indagaciones académicas.

${ }^{3}$ Para una discusión en profundidad sobre Estado del Bienestar keynesiano-fordista ver Polanyi (1957), Titmuss (1958), Rossanvallon (1981), Spicker (1988), entre otros. 


\section{Regímenes de Bienestar: conceptos que innovan los análisis y las políticas}

Como se indicó, el concepto de Régimen de Bienestar busca superar los modelos teóricos clásicos del estudio del Estado de Bienestar y las políticas sociales. Estos presentaban un análisis demasiado fragmentado y a-político (o a-ideológico) de la realidad, como si los proyectos de país no tuvieran que ver con las políticas sociales diseñadas e implementadas. De esta manera, los continuos y tipologías que se establecían en la literatura del bienestar y el cuidado en un pasado podían no dar cuenta realmente del tipo de modelo general que se estaba construyendo. Así pues, las obras seminales de Esping-Andersen (1993, 2000) supusieron un enriquecimiento cognitivo que permitió: 1) construir una mirada integral más allá de la fragmentación sectorial de análisis previos, focalizados en un tipo concreto de políticas como las educativas, sanitarias, de seguro social, etc.; e 2) integrar los análisis sin perder de vista que el objetivo último era dar cuenta del modelo de sociedad que se estaba construyendo con tales intervenciones, es decir "mirar el árbol sin perder de vista el bosque". A esto se deben agregar otros tres aportes fundamentales: 3) superar una aproximación cuantitativista, basada exclusivamente en el análisis de la cantidad de dinero que se gasta y no en el cómo se gasta, "sociologizando" el análisis; 4) considerar no solamente la esfera público-estatal como productora de bienestar sino también tener en cuenta la esfera mercantil, la comunitaria o social y la familiar; y, 5) facilitar el desarrollo de aproximaciones comparativas entre países y modelos.

Esta nueva agenda posibilitaba la comprensión de la naturaleza de las diferentes esferas implicadas en la prestación de bienestar y cuidado, más allá del Estado. Como apuntan Gallego, Gomà y Subirats (2003:47): "las políticas de bienestar se conforman como espacios de gestión colectiva de los múltiples ejes de desigualdad — de clase, de ciudadanía, de género, etc.—, que surcan múltiples esferas — pública, mercantil, asociativa, familiar - ". Si una necesidad no es cubierta por el Estado, muy probablemente recaerá sobre otra esfera. Analizar por lo tanto el bienestar desde esta visión más amplia permite no sólo mejorar los diagnósticos sino también las orientaciones en materia de políticas públicas.

\subsection{Regímenes de Bienestar en América Latina}

Si bien existen diversas investigaciones previas sobre tipologías de países latinoamericanos analizando sus políticas sociales ${ }^{4}$, la investigación más completa realizada hasta el momento sobre Regímenes de Bienestar en la región es la llevada a cabo por Martínez Franzoni (2007), situando su trabajo de campo entre 1998 y 2003, operando a partir del concepto de Regímenes de Bienestar de Esping-Andersen (1993, 2000) y

\footnotetext{
${ }^{4}$ Ver Mesa-Lago (1991), Filgueira (1998), Barba (2005), etc.
} 
agregando perspectivas feministas como la de Orloff $(1993,2009)$. A partir de una visión integral de la política pública, en su modelo analítico da importancia al trabajo productivo y reproductivo, además de analizar los servicios de salud y educación, y los niveles de protección social. Esta autora apunta que "todos los regímenes latinoamericanos son, en alguna medida, informales, en tanto una proporción de la población no puede (...) lidiar razonablemente con los riesgos sociales a través de su participación en los mercados laborales o en los servicios públicos (Gough y Wood, 2004). Por lo tanto, una proporción variable de la población en alguna medida depende de arreglos familiares y comunitarios" (Martínez Franzoni, 2007: 23-24).

La autora elabora una tipología completa y compleja dibujando para la región latinoamericana tres modelos de regímenes de bienestar: estatal-proteccionista, estatal-productivista y familiarista. Considera como regímenes estatal-productivista los casos de Argentina y Chile: "El Estado interviene en aquellas áreas en que el mercado no resuelve o para aquella parte de la población para la cual el intercambio mercantil no es suficiente" (2007: 24). El objetivo fundamental es conseguir una fuerza laboral con buenas condiciones para que participe con éxito en el mercado laboral. Estos países han logrado comparativamente mercantilizar su fuerza de trabajo de manera más abarcante que el resto de países, aunque la protección de riesgos (vejez) y la formación de capital humano (salud y educación) aún dependen de manera importante del poder adquisitivo de la población. Martínez Franzoni sitúa como regímenes estatal-proteccionistas los casos de Brasil, Costa Rica, México, Panamá y Uruguay: "el Estado en este caso interviene aún en áreas que podrían ser de predominio del mercado (como la seguridad social) y para población que no necesariamente se encuentra en condiciones de pobreza" (2007: 24). En este tipo de países las medidas ponen el acento en la protección social, pero de manera prioritaria en las contribuciones asociadas al trabajo formal. Estos territorios tienen un grado menor de mercantilización de la fuerza de trabajo que los anteriormente citados, pero en términos de protección social y formación de capital humano son superiores, aunque con una fragmentación de grupos sociales. Luego, señala como regímenes familiaristas dos grupos de casos: 1) Colombia, Ecuador, El Salvador, Guatemala, Perú, República Dominicana y Venezuela; 2) Bolivia, Honduras, Nicaragua y Paraguay. Estos tienen un peso importante de prácticas informales, aquí "la mayoría de la población depende solo de arreglos familiares y comunitarios en el marco de mercados laborales y políticas públicas excluyentes" (Martínez Franzoni, 2007: 25). La diferencia entre los dos grupos de países es de grado. Un número importante de la población no tiene un buen acceso a los servicios públicos. Estos países tienen muy poca capacidad para absorber la fuerza de trabajo y hacerlo con calidad. Finalmente, indica que las tasas de pobreza en estos países son altas.

Expuesta la tipología, se requiere estudiar los Regímenes de Bienestar en América Latina con posterioridad al periodo de irrupción de las propuestas neoliberales ${ }^{5}$. Si bien

\footnotetext{
${ }^{5}$ Sobre modelo económico y social construido en el período neoliberal ver Deniz (2006) y Palazuelos (2000).
} 
el trabajo de Martínez Franzoni (2007) nos abre una interesante perspectiva de análisis, la limitación del periodo temporal en que ella sitúa el trabajo de campo nos empuja a pensar que es interesante desarrollar estudios sobre los gobiernos llamados "progresistas o de izquierda" que se constituyen en América Latina en cascada a partir del triunfo de Chávez en 1998. La hipótesis es que con la irrupción de estos nuevos proyectos políticos, el mapa de los modelos de bienestar y cuidado podría haber cambiado de manera substantiva. Y no se trata solamente de cambios de los países en las categorías dibujadas por la autora, sino que podría suponer un replanteamiento mismo de las propias categorías.

Como ya se ha apuntado anteriormente, a pesar de que las experiencias transformadoras son distintas por las diversas realidades económico-sociales y de acción política en las que se asientan, éstas poseen varios puntos de contacto y caminan hacia prestar una mayor respuesta a las necesidades sociales desde el propio Estado. La centralidad que ha tomado la agenda social en sentido extenso en los procesos de transformación, sobre todo de manera importante en los casos de Ecuador, Bolivia y Venezuela, hace pensar que se podría estar abandonando la caracterización exclusiva de un régimen familiarista que daba la autora con datos de 1998-2003. Así pues, el Estado interviene en áreas que podrían ser de predominio del mercado, la sociedad y hasta la familia, y se amplía la cobertura, el gasto e inclusive la calidad del servicio en salud, educación, protección social y habría algunos avances a nivel del mercado laboral y de la protección asociada a dicho ámbito, entre otras mutaciones. A continuación se muestran algunas de estas transformaciones mediante indicadores cuantitativos ${ }^{6}$, en concreto se puede visualizar: 1) más ingresos del Estado y mayor gasto público, y en concreto gasto social; 2) expansión de los servicios de salud, educación y protección social (más gasto y mejores resultados); 3 ) mejoras en la calidad del mercado de trabajo; y, en parte como consecuencia de lo anterior, 4) reducción de la pobreza y la desigualdad.

${ }^{6}$ Datos obtenido de CEPALSTAT. Base de datos y Publicaciones Estadísticas" de la Comisión Económica para América Latina y Caribe (CEPAL). Ver <http://estadisticas.cepal.org/cepalstat/WEB CEPALSTAT/Portada.asp> (consultado por última vez el 12 de junio de 2015). Se han seleccionado tres momentos temporales relevantes para el estudio de los países de nuestra consideración, buscando también que se pudiera mantener una lógica comparativa entre países. Se apuntan indicadores de proceso y de resultado de manera indistinta en la tabla. La intención es tener una mirada comprensiva sobre las dinámicas de continuidad y cambio acaecidas en estos países. 


\section{Los casos de Ecuador, Venezuela y Bolivia}

Tabla 1: Algunos indicadores sobre bienestar en Venezuela, Ecuador y Bolivia: DINÁMICAS DE CONTINUIDAD Y CAMBIO

\begin{tabular}{|c|c|c|c|c|c|c|c|}
\hline & \multicolumn{2}{|c|}{ Ecuador } & \multicolumn{2}{|c|}{ Bolivia } & \multicolumn{3}{|c|}{ Venezuela } \\
\hline & 2005 & 2012 & 2005 & 2012 & 1997 & 2005 & 2012 \\
\hline \multicolumn{8}{|c|}{ 1. Más ingresos Estado y mayor gasto público } \\
\hline $\begin{array}{l}\text { Deuda externa } \\
\text { como porcentaje del PIB }\end{array}$ & 41,53 & 18,16 & 80,28 & 24,79 & 43,39 & 31,91 & 30,29 \\
\hline $\begin{array}{l}\text { Ingresos del gobierno central } \\
\text { como porcentaje PIB }\end{array}$ & 14,6 & 22,3 & ND & ND & 23,8 & 27,5 & 23,5 \\
\hline $\begin{array}{l}\text { Gastos del gobierno central } \\
\text { como porcentaje PIB }\end{array}$ & 15 & 24,2 & ND & ND & 21,9 & 25,9 & 28,4 \\
\hline \multicolumn{8}{|c|}{ 2. Expansión de los servicios de educación, sanidad y protección social } \\
\hline $\begin{array}{l}\text { Gasto público en salud } \\
\text { como porcentaje PIB }\end{array}$ & 6,3 & 6,4 & 5,6 & 5,8 & 4,2 & 5,4 & 4,7 \\
\hline $\begin{array}{l}\text { Gasto público en educación } \\
\text { como porcentaje PIB }\end{array}$ & ND & 4,4 & $\begin{array}{c}6,3 \\
(2006)\end{array}$ & 6,4 & ND & $\begin{array}{c}3,7 \\
(2006)\end{array}$ & $\begin{array}{c}6,9 \\
(2009)\end{array}$ \\
\hline $\begin{array}{l}\text { Tasa neta de matrícula } \\
\text { educación secundaria }\end{array}$ & 53,6 & 74 & $\begin{array}{c}68,9 \\
(2006)\end{array}$ & 69,8 & $\begin{array}{c}47,8 \\
(1999)\end{array}$ & 62,8 & 74,3 \\
\hline $\begin{array}{l}\text { Tasa de mortalidad infantil } \\
\text { (por } 1000 \text { nacidos vivos) }\end{array}$ & 24,1 & 19,7 & 44 & 32,2 & 20,5 & 15,8 & 13,2 \\
\hline \multicolumn{8}{|c|}{ 3. Mejoras en la calidad del mercado de trabajo } \\
\hline Tasa desempleo & 8,5 & 4,9 & 8,2 & $\begin{array}{c}6,5 \\
(2010)\end{array}$ & 11,4 & 12,3 & 8,1 \\
\hline $\begin{array}{l}\text { Ocupados urbanos } \\
\text { en el sector informal } \\
\text { del mercado de trabajo }\end{array}$ & 57,3 & 54 & $\begin{array}{c}69,9 \\
(2004)\end{array}$ & $\begin{array}{c}60 \\
(2011)\end{array}$ & 46,5 & 53,7 & 50,1 \\
\hline \multicolumn{8}{|c|}{ 4. Reducción pobreza y desigualdad } \\
\hline Pobreza & 48,3 & $\begin{array}{c}33,6 \\
(2013)\end{array}$ & $\begin{array}{c}63,9 \\
(2004)\end{array}$ & $\begin{array}{c}36,3 \\
(2011)\end{array}$ & 48 & 37,1 & 25,4 \\
\hline Indigencia & 21,2 & $\begin{array}{c}12 \\
(2013)\end{array}$ & $\begin{array}{c}34,7 \\
(2004)\end{array}$ & $\begin{array}{c}18,7 \\
(2011)\end{array}$ & 20,5 & 15,9 & 7,1 \\
\hline Gini & 0,53 & $\begin{array}{c}0,48 \\
(2013)\end{array}$ & $\begin{array}{c}0,56 \\
(2004)\end{array}$ & $\begin{array}{c}0,47 \\
(2011)\end{array}$ & 0,51 & 0,49 & 0,41 \\
\hline
\end{tabular}

Fuente: Elaboración propia a partir de CEPALSTAT. Base de datos y Publicaciones Estadísticas. 


\section{Tabla 2: El bienestar en las Constituciones de Venezuela, Ecuador y Bolivia}

\begin{tabular}{|c|c|c|c|}
\hline & Venezuela (1999) & Ecuador (2008) & Bolivia (2009) \\
\hline & $\begin{array}{l}\text { "Venezuela se constituye en un } \\
\text { Estado democrático y social de } \\
\text { Derecho y de Justicia( )" (2) }\end{array}$ & $\begin{array}{l}\text { "El Ecuador es un Estado constitu- } \\
\text { cional de derechos y justicia, social, } \\
\text { democrático, soberano, independi- } \\
\text { ente, unitario, intercultural, plurina- } \\
\text { cional y laico" (1) }\end{array}$ & $\begin{array}{l}\text { "Bolivia se constituye en un Estado } \\
\text { Unitario Social de Derecho Pluri- } \\
\text { nacional Comunitario ( ), y asegura } \\
\text { el desarrollo equitativo mediante } \\
\text { la redistribución de los excedentes } \\
\text { económicos en políticas sociales, de } \\
\text { salud, educación y cultura" (1) }\end{array}$ \\
\hline 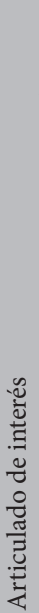 & $\begin{array}{l}\text { Derechos sociales y de las familias } \\
\text { (familia } 75-77 \text {; niños, niñas y ado- } \\
\text { lescentes } 78 \text {; jóvenes } 79 \text {; ancianos } 80 \text {; } \\
\text { discapacidad } 81 \text {; vivienda } 82 \text {; salud } \\
83-85 \text {; seguridad social } 86 \text {; trabajo } \\
87-97 \text { ) } \\
\text { Derechos culturales y educativos } \\
\text { (98-111) } \\
\text { Fiscal y tributario ( } 311 \text { y } 316)\end{array}$ & $\begin{array}{l}\text { Derechos del buen vivir (agua y ali- } \\
\text { mentación } 12 \text { y } 13 \text {; educación } 26-29 \text {, } \\
\text { hábitat y vivienda } 30-31 \text {, salud } 32 \text {, } \\
\text { trabajo y seguridad social 33-34) } \\
\text { Derechos de las personas y grupos } \\
\text { de atención prioritaria (adultas y } \\
\text { adultos mayores } 36-38 \text {; jóvenes } 39 \text {; } \\
\text { mujeres embarazadas } 43 \text {; niños, } \\
\text { niñas y adolescentes } 44-46 \text {; personas } \\
\text { con discapacidad } 47-49 \text {; personas } \\
\text { con enfermedades catastróficas } 50 \text {; } \\
\text { personas privadas de libertad 51) } \\
\text { Política fiscal (285) Régimen tribu- } \\
\text { tario (300-301) } \\
\text { Régimen del buen vivir. Inclusión y } \\
\text { equidad (340-341) (educación } 343- \\
\text { 357, salud 358-366, seguridad social } \\
\text { 367-374, hábitat y vivienda } 375-376 \text { ) }\end{array}$ & $\begin{array}{l}\text { Derechos fundamentalísimos (edu- } \\
\text { cación } 17 \text {, salud } 18 \text { y vivienda } 19 \text { ) } \\
\text { Derechos sociales, económicos y } \\
\text { culturales (salud y seguridad social } \\
\text { 35-47; trabajo y empleo 46-55; } \\
\text { niñez 58-61; familias 62-66; adultos } \\
\text { mayores 67-69; discapacidad 70-72; } \\
\text { privadas de libertad 73-75) } \\
\text { Educación e interculturalidad (edu- } \\
\text { cación 78-91; educación superior } \\
92-99 \text { ) } \\
\text { Política tributaria (321) }\end{array}$ \\
\hline & $\begin{array}{l}\text { Dentro del apartado "derechos } \\
\text { sociales y de las familias" se contem- } \\
\text { plan derechos vinculados al ciclo de } \\
\text { vida, derechos básicos de bienestar } \\
\text { y se visualiza de manera mucho más } \\
\text { amplia que los anteriores derechos el } \\
\text { trabajo. Aparece la familia de manera } \\
\text { importante entendida como "aso- } \\
\text { ciación natural de la sociedad" (75) } \\
\text { Vincula de manera fuerte derechos } \\
\text { sociales al derecho de trabajo digno } \\
\text { y de calidad } \\
\text { Vinculación de la prestación de } \\
\text { servicios a la extracción de materias } \\
\text { primas: "El ingreso que se genere } \\
\text { por la explotación de la riqueza del } \\
\text { subsuelo y los minerales, en general, } \\
\text { propenderá a financiar la inversión } \\
\text { real productiva, la educación y la } \\
\text { salud" (311) }\end{array}$ & $\begin{array}{l}\text { Primero enunciación de los derechos } \\
\text { (algunos los conceptualiza como } \\
\text { derechos del buen vivir) y después } \\
\text { desarrollo de estos. } \\
\text { Dentro del régimen del buen vivir } \\
\text { se establece un sistema nacional de } \\
\text { inclusión y equidad ( } 340 \text { ). } \\
\text { Se hacer referencia a distintos mo- } \\
\text { mentos del ciclo de vida, utilizando } \\
\text { el concepto de grupos de atención } \\
\text { prioritaria. } \\
\text { Existe transversalidad entre políticas } \\
\text { sociales clásicas y otras políticas. } \\
\text { También se detecta voluntad de } \\
\text { relación del "mundo" social y el } \\
\text { "mundo" económico. } \\
\text { Uso del concepto del Buen Vivir, que } \\
\text { va más allá del bienestar. }\end{array}$ & $\begin{array}{l}\text { Primero enunciación de los derechos } \\
\text { (algunos los conceptualiza como } \\
\text { derechos fundamentalísimos) y } \\
\text { después desarrollo de estos. } \\
\text { Dentro del apartado "derechos } \\
\text { sociales, económicos y culturales" se } \\
\text { contemplan derechos vinculados al } \\
\text { ciclo de la vida, derechos básicos de } \\
\text { bienestar y se visualiza el trabajo. } \\
\text { Uso del concepto de "derechos fun- } \\
\text { damentalísimos", de rango superior a } \\
\text { los "derechos fundamentales". }\end{array}$ \\
\hline
\end{tabular}

Fuente: Elaboración propia a partir de las Constituciones de Venezuela (1999), Ecuador (2008) y Bolivia (2009). 
Aunque los procesos de retorno del Estado y de búsqueda de superación del modelo neoliberal se producen en distintos países de América Latina, en el presente artículo se analizan solamente los casos de Ecuador, Venezuela y Bolivia. Se ha procedido a la selección de estos referentes por cuatro motivos: 1) Los tres países vivieron procesos constituyentes que implicaron cambios substantivos, desde la misma Carta Magna, en la manera de entender el bienestar y el cuidado de la población; 2) durante los años que han dirigido el Estado gobiernos denominados como "progresistas" o de "izquierda" se han puesto en marcha importantes estrategias de retorno del Estado en el ámbito de la regulación, la planificación y el desarrollo de políticas públicas en la agenda social y económica; y (3) los tres países fueron tipificados como regímenes familiaristas por Martínez Franzoni (2007) en plena etapa neoliberal, se trata de países andinos con presencia de población indígena y niveles altos de pobreza y desigualdad; 4) se trata de países poco estudiados desde una perspectiva de bienestar y cuidados.

Se considera pues que son los tres casos donde se han producido modificaciones normativas (constitucionales, legales), programáticas y en las políticas públicas con una intensidad relevante y que merecen ser estudiados de manera detallada (Stefanoni, 2011). A continuación se presenta una primera exploración a los Regímenes de Bienestar que se construyen en estos países, dejando para futuros trabajos una descripción densa y un análisis detallado de los mismos. También en un futuro será interesante añadir nuevos casos para construir una mirada comparada más amplia. Así pues, es objetivo principal de este texto empezar a poner en discusión los cambios acontecidos, identificar dinámicas de continuidad y cambio en las agendas sociales y económicas de estos procesos de transformación y consolidar una línea de investigación y debate que se concentre en estas cuestiones que nos pueda llevar a la reconstrucción de una nueva cartografía de bienestar en América Latina.

\subsection{El bienestar en las nuevas constituciones}

Los procesos constituyentes desarrollados en los tres países citados marcan un antes y un después en las reglas de juego de la política, las políticas y la gestión públicas. Constitucionalistas como Viciano y Martínez (2010) apuntan que la ola de creación de nuevas constituciones latinoamericanas en el cambio de milenio tiene unas características propias. De esta manera, las constituciones de Venezuela (1999), Ecuador (2008) y Bolivia (2009) conformarían el "nuevo constitucionalismo latinoamericano" que iría más lejos del "neoconstitucionalismo" que inspiró, entre otras, las Cartas Magnas del Estado español (1978) y de Brasil (1988). Las peculiaridades se refieren sobre todo al procedimiento adoptado para la construcción de dichas cartas políticas, lo cual supondrá inevitablemente cambios sustantivos de contenido.

Así pues, desde el punto de vista externo, los tres procesos latinoamericanos "asumen la necesidad de legitimar la voluntad social de cambio mediante un intachable 
proceso constituyente de hechura democrática $y$, aunque los resultados son en buena medida desiguales, consiguen aprobar constituciones que apuntan, en definitiva, hacia el Estado constitucional. Teoría y práctica se unen, por lo tanto, en el nuevo constitucionalismo latinoamericano" (Viciano y Martínez, 2010: 26). Se pone pues énfasis en los mismos procesos de construcción de estas constituciones que se abren a la participación de numerosos actores políticos y sociales, así como utilizando prolongados procesos de deliberación.

Desde el punto de vista interno se han apuntado también diferencias respecto a constituciones anteriores. Así pues, según Martínez Dalmau (2008: 75) se destaca: "su contenido innovador (originalidad), la ya relevante extensión del articulado (amplitud), la capacidad de conjugar elementos técnicamente complejos con un lenguaje asequible (complejidad) y el hecho de que se apuesta por la activación del poder constituyente del pueblo ante cualquier cambio constitucional (rigidez)". Ahora bien, desde la posición del presente artículo se sostiene que en lo que se refiere a estos aspectos "internos" las diferencias con el "neoconstitucionalismo" no son tan relevantes como los autores citados plantean. Se produce simplemente un proceso de construcción de constituciones en un nuevo contexto político, social y cultural. Eso es, las constituciones se adaptan a su tiempo. Así pues, textos de este tipo en el presente tendrán nuevas agendas (con nuevas conquistas), mayores complejidades y articulados mucho más amplios y hasta detallados. Y no serán solamente características de las Cartas Magnas de Venezuela, Bolivia y Ecuador.

En cuanto a lo que se refiere a la constitucionalización del modelo de bienestar que se dibujará en un futuro en los países bajo análisis, cabe decir que en los tres casos supone un salto relevante respecto a las normativas constitucionales precedentes.

\subsection{La caracterización de las políticas de bienestar en los tres países}

Como se mencionó, Martínez Franzoni (2007) identificó, con datos de 1998-2003, a los tres países estudiados como regímenes familiaristas (Ecuador y Venezuela los situaba en el primer grupo y Bolivia en el segundo). Aunque algunas de las características que apuntaba la autora actualmente se mantienen — son importantes aún los arreglos familiares y comunitarios en el ámbito laboral y de cuidados - el retorno del Estado y la búsqueda activa de materialización de políticas progresistas matizaría la afirmación de dificultad de acceso a servicios públicos como la salud o la educación, así como también debería tenerse en cuenta una cierta dinamización y el aumento de calidad en la fuerza de trabajo que se ha producido durante los últimos años. Además hay que apuntar que las tasas de pobreza y desigualdad, si bien aún son altas, han disminuido de manera destacada y sostenida en los tres países. A continuación se realiza una aproximación cualitativa a la construcción del régimen de bienestar en los países estudiados, descripción que acompañará a los datos cuantitativos antes expuestos. Las estadísticas son útiles 
porque describen la panorámica general de una realidad concreta. Pero para avanzar en la interpretación requerimos también de aproximaciones más cualitativas, de comprensión del modelo en construcción. Este es el objetivo de los apartados que siguen.

\subsubsection{Ecuador: planificación, extensión de los servicios y búsqueda de la calidad ${ }^{7}$}

De entrada es factible afirmar que la Constitución de Montecristi (2008) asienta las bases para la formación de un Régimen de Bienestar que supere los modelos anteriores. Más allá de la Ley Fundamental, que como se ha visto anteriormente supone un salto hacia adelante, cabe decir que las políticas públicas implementadas durante estos seis años - de destacada calidad gracias al sistema de planificación que se construye en el país y con una fuerte inversión de recursos públicos- aportan importantes avances en el campo social y a la vista están los indicadores sobre logros conseguidos (Ramírez y Minteguiaga, 2007; Minteguiaga 2012). Como en todo proceso político real, se trata de un Régimen en construcción y disputa, tanto entre gobierno y actores sociales y empresariales, como (y ésta es una característica relevante para el caso del Ecuador) dentro el propio Ejecutivo y otras instancias y poderes estatales.

Durante los primeros seis años de la "Revolución Ciudadana" se identifican tres claras dinámicas que deben ser expuestas para entender el modelo en construcción: 1) La (re)apropiación de recursos para el Estado; una porción importante de estos que restaban enajenados por la deuda externa, por el lucro de las empresas multinacionales explotadoras de petróleo o minería, y por la negativa de las clases adineradas de pagar impuestos, vuelven a manos de los poderes públicos. 2) La recuperación de la autonomía (relativa) del Estado y su capacidad de planificación; se produce un proceso de descorporativización del Estado y un retorno de la capacidad de los poderes públicos a la rectoría, regulación, control y planificación de la acción pública ${ }^{8}$. 3) La fuerte inversión social y extensión de políticas de bienestar; aumenta la cantidad de recursos que se destinan al desarrollo de políticas sociales, así como también las coberturas de estos servicios. En este sentido, saltan a la vista los importantes avances en indicadores de bienestar social y desarrollo humano: disminución de pobreza y desigualdad, aumento de coberturas de salud y educación, consiguiendo una universalización de mínimos, y mejoras en la calidad de la fuerza de trabajo (más trabajo pleno y más trabajadores afiliados a la seguridad social) 9 .

${ }^{7}$ Para el caso ecuatoriano ver una descripción más detallada en Minteguiaga y Ubasart (2013a y 2013b).

${ }^{8}$ Sobre las transformaciones estatales operadas en el país ver Ramírez (2012a y 2012b) y Muñoz (2013).

${ }^{9}$ En el periodo 2007-2012 la tasa de empleo en Ecuador (o ocupación plena) ha pasado de del 34,2\% de la PEA al 42,3\%. Por lo tanto, puede firmarse que las tendencias adoptan una dirección positiva pero no se detecta un cambio estructural en la composición de la PEA. En cuanto las tasas de afiliación a la seguridad social, éstas aumentan en el periodo 2007-2012 (de un 26,3\% respecto a la PEA en enero de 2007 a 
De todas formas se detectan aún importantes tendencias que vienen del periodo neoliberal: focalización y estructuras familiaristas permanecen en muchas políticas de inclusión y protección social (el ejemplo del Bono de Desarrollo Humano o las políticas de discapacidad — Bono Manuela Espejo y Joaquín Gallegos Lara- como paradigmáticas); la centralidad que toma la lucha contra la pobreza o las políticas de desarrollo infantil (ambas de corte asistencial) en la agenda social; la dualidad en la prestación de servicios de salud y educación (las clases populares en servicios prestados por el Estado, las clases medias y altas en servicios privados comprados en el mercado), etc.; y un mercado laboral aún con importantes niveles de informalidad y desprotección. Asimismo, se identifican tres características que pueden re-direccionar el Régimen de Bienestar de Ecuador y que se presentan como potencialidades de futuro, y no solo en términos cuantitativos de extensión de gasto público y coberturas, sino también en términos cualitativos de modificación del modelo: 1) La centralidad de la planificación nacional; 2) La preocupación por la calidad de los servicios públicos; y 3) La importancia que se le está dando al sistema tributario y sus cargas diferenciales según niveles socioeconómicos.

Entrando en la primera, el Sistema Nacional Descentralizado de Planificación Participativa se dibuja en la propia Constitución (arts. 279-280) y se desarrolla en el Código de Planificación y Finanzas Públicas, y en un segundo plano en la Ley Orgánica de Participación Ciudadana y el Código Orgánico de Organización Territorial, Autonomía y Descentralización. A razón de este cuerpo normativo, cada nueva legislatura tiene que ir precedida por la elaboración de un Plan Nacional del Buen Vivir (o Plan de Desarrollo) (SENPLADES, 2007; 2009; 2013) que es de obligado cumplimiento por parte de todos los poderes públicos. Las instituciones sub-nacionales también tienen que planificar sus actuaciones. Además, el desarrollo y el cumplimiento del Plan se lleva a cabo con instrumentos técnicos de alta calidad: seguimiento mediante indicadores y evaluaciones, encuestas y estadísticas, procedimientos estandarizados públicos y transparentes, etc. Este hecho puede jugar a favor de la consecución de políticas públicas eficaces, eficientes y democráticas en el campo social, fiscal, laboral y tributario.

Vinculado a lo anterior, y como segunda característica, el gobierno de la "Revolución Ciudadana" pone un énfasis grande en la consecución de la calidad. No es de extrañar el acento puesto en la meritocracia o en el control de la implementación de políticas públicas mediante distintos mecanismos de gestión pública y seguimiento de las acciones institucionales. En el propio Programa de Gobierno con el que el presidente Rafael Correa gana las elecciones en febrero de 2013, la cuestión de la calidad está presente, así como en distintos objetivos del Plan Nacional del Buen Vivir 20132017. Conseguir calidad en los servicios de educación y salud puede romper la dualidad existente actualmente entre el mercado público y el mercado privado de servicios

un $42,3 \%$ en enero de 2013) pero aún existe una parte importante del mercado de trabajo que no entra en el mundo de la seguridad social (Minteguiaga y Ubasart-Gonzàlez, 2013b: 56-57). 
(Minteguiaga y Ubasart-González, 2013b: 29-32). También, la posibilidad de repensar las políticas de inclusión y protección social en este marco pueden proyectar unas respuestas de acción pública emancipadoras en un futuro.

La tercera característica se encuentra en la importancia que se le da al sistema tributario. Ha sido una prioridad del gobierno hacer un sistema tributario eficaz y eficiente y progresivo, que empiece a cumplir sus funciones distributivas y redistributivas. Si bien es cierto que no se ha llevado a cabo una reforma estructural que permita una transferencia radical de rentas entre estratos sociales, sí es cierto que se ha conseguido lograr el cumplimiento de las leyes tributarias existentes, el aumento sostenido de las cargas tributarias con sentido "pro-pobre", así como una credibilidad en la institución receptadora que abre la puerta a la consolidación de un modelo integral que vincule agenda social y tributaria ${ }^{10}$.

\subsubsection{Venezuela: construcción de una nueva institucionalidad pública}

En el caso venezolano la construcción del modelo tiene una década y media de vida y presenta unas características más concretas que permiten hacer una mayor definición de este ${ }^{11}$. De todas formas, la "Revolución Bolivariana" es un proceso en marcha y eso hace que se puedan identificar distintos períodos en la construcción del régimen de Bienestar del país, destacando al menos tres etapas, que pueden identificarse tanto en el plano económico-productivo como social.

En el plano económico y ligado al retorno del Estado se identifica un primer ciclo de corte "ortodoxo" (Guerra, 2009: 1)12. Así, a pesar de la inauguración de un "discurso modernizador en cuanto al modelo de desarrollo, interclasista en lo social, nacionalista en sus aspectos aglutinadores y anti-neoliberal" (Mateo Tomé y Sánchez Iglesias, 2010: 2900) la vertiente macroeconómica mantiene un perfil fiscalista con centralidad en el control del déficit presupuestario y la inflación, toda vez que hace de estas gestiones "sostenibles el pivote para articular el resto de las políticas económicas: la sostenibilidad fiscal supone mantener una dinámica cambiaria de estabilización que se seguirá inscribiendo como ancla cambiaria" (Guerra, 2009: 1). A fines de 2001 la Asamblea Nacional aprueba las "leyes habilitantes" — la Ley de Pesca y Acuacultura, la Ley de

${ }^{10}$ La recaudación tributaria en relación al PIB pasa de un 9,1 en 2000 a un 12,3 en 2011 (SENPLADES, 2013: 115).

${ }^{11}$ Cabe decir que a diferencia del caso ecuatoriano, existe bastante literatura experta sobre políticas sociales sectoriales, en concreto sobre las "misiones", pero hay pocos datos y trabajos empíricos (ni gubernamentales ni de otras instituciones) a los que recurrir para hacer una evaluación detallada y objetiva. Las prioridades de investigación en el caso venezolano se han centrado en otros campos, diversos a las políticas sociales integrales, laborales y tributarias que son las que en este artículo se hace referencia.

12 Véase el documento "La Propuesta de Hugo Chávez para transformar a Venezuela: Una revolución democrática (MPD, 1999). 
Tierras y Desarrollo Agrario y la Ley Orgánica de Hidrocarburos- que tenían como objetivo hacer converger el discurso político que empieza a tomar el bloque bolivariano (nacional-popular) y la propuesta económica del mismo. En concreto, la ley de hidrocarburos resulta clave ya que plantea la recuperación de la soberanía petrolera ("renacionalización") y rompe la política de apertura petrolera y el programa de internacionalización de PDVSA. En paralelo se diseña una reforma impositiva para elevar los ingresos estableciendo la regalía como figura básica y fijándola en el 30\% (frente al 16\% anterior) a la vez que se reduce el impuesto sobre la renta del 59 al 50\% (Mateo Tomé y Sánchez Iglesias, 2010: 2906).

TABLA 3: ETAPAS DE DESARROLLO DEL MODELO VENEZOLANO

\begin{tabular}{|c|c|c|c|}
\hline & $\begin{array}{l}\text { Primera etapa: } \\
\text { 1999-2003 }\end{array}$ & $\begin{array}{l}\text { Segunda etapa: } \\
\text { 2003-2007 }\end{array}$ & $\begin{array}{l}\text { Tercera etapa: } \\
\text { 2007-2012 }\end{array}$ \\
\hline $\begin{array}{l}\text { Plano } \\
\text { económico-productivo }\end{array}$ & $\begin{array}{l}\text { Política macreconómica } \\
\text { de corte ortodoxo. } \\
\text { Aprobación "leyes habili- } \\
\text { tantes" }\end{array}$ & $\begin{array}{l}\text { Fase expansiva: subida } \\
\text { precios petróleo. } \\
\text { Se inicia política de control } \\
\text { de precios y de cambios }\end{array}$ & $\begin{array}{l}\text { Nacionalizaciones de } \\
\text { empresas estratégicas }\end{array}$ \\
\hline Plano social & $\begin{array}{l}\text { Políticas de carácter } \\
\text { continuista respecto al } \\
\text { pasado, se ratifican la } \\
\text { mayor parte de progra- } \\
\text { mas sociales del gobierno } \\
\text { anterior }\end{array}$ & $\begin{array}{l}\text { Creación y expansión de } \\
\text { las misiones, modelo pro- } \\
\text { pio de diseño e implemen- } \\
\text { tación políticas sociales }\end{array}$ & $\begin{array}{l}\text { Desaceleración experi- } \\
\text { encia misiones y reestruc- } \\
\text { turación permanente } \\
\text { agenda social }\end{array}$ \\
\hline $\begin{array}{l}\text { Programas } \\
\text { o leyes destacadas }\end{array}$ & & $\begin{array}{l}\text { Proyecto Nacional Simón } \\
\text { Bolivar } \\
\text { Primer Plan Social- } \\
\text { ista (PPS) de Desarrollo } \\
\text { Económico y Social de la } \\
\text { Nación (2007-2013) }\end{array}$ & $\begin{array}{l}\text { Ley de Defensa de las } \\
\text { Personas en el Acceso a } \\
\text { los Bienes y Servicios }\end{array}$ \\
\hline
\end{tabular}

Fuente: Elaboración propia a partir de Guerra (2009) y Maingón (2004).

Estas medidas generan conflicto y su resolución tendrá que esperarse hasta el 20032004. Por un lado se inicia una subida de los precios del petróleo en 2003, que alcanzará su cénit hacia 2005-2007, iniciándose una fase expansiva. Por el otro, el conflicto con el bloque opositor pierde fuelle con la ratificación del mandato de Hugo Chávez en el referéndum revocatorio del 15 de agosto de 2004 (Guerra, 2009: 2). A partir de aquí se fortalece el papel del Estado como regulador y como empresario y se inicia una política de control de precios y control de cambios. Desde 2005 se empieza a hablar de "socialismo del siglo XXI" y este hecho se ve reflejado en el Proyecto Nacional Simón Bolivar o Primer Plan Socialista (PPS) de Desarrollo Económico y Social de la Nación (2007-2013). El problema de la economía venezolana a partir de aquel momento 
ya no se comprenderá en términos de atraso tecnológico y productivo o su estructura económica y su necesidad de modernizarla, sino por la existencia del propio sistema capitalista y la relación capital-trabajo ${ }^{13}$.

En 2008 se aprueba la Ley de Defensa de las Personas en el Acceso a los Bienes y Servicios, mediante la cual se le da un poder casi ilimitado al gobierno para declarar de utilidad pública cualquier actividad económica o clausurar establecimientos comerciales, aumentando las posibilidades de expropiación. En 2009, y a fin de controlar la totalidad de la cadena productiva de la industria petrolera, se nacionalizan 76 empresas del lago de Maracaibo.

En cuanto al campo estricto de la agenda social, desde 1998 en que Chávez gana las elecciones, se empezaron a dar pasos con la finalidad de luchar contra la pobreza y la desigualdad. Los índices de miseria y extrema pobreza eran alarmantes en diversas zonas del país como resultado, en parte, del periodo neoliberal experimentado. Como ya se ha visto, la Constitución de 1999 presenta importantes innovaciones. Se amplía el reconocimiento de los derechos sociales y además se plantea un nuevo contexto en el que estos deberán construirse poniendo en el centro la corresponsabilidad entre ciudadanos y Estado. Así pues, "la política social debe tener como finalidad capacitar, preparar y garantizar la salud, el trabajo, la educación, la seguridad social, la vivienda. En fin, construir una ciudadanía de contenido social" (Maingón, 2004: 55). Aparte de la Carta Magna, otros instrumentos orientan la agenda social en este periodo: el Plan Bolivar 2000, que incluye la Agenda Social 2000, y el ya mencionado Plan de Desarrollo Económico y Social de la Nación 2001-2007 (PDES).

De todas formas, la urgencia por operar, vista la magnitud de los indicadores sociales del momento, lleva al gobierno bolivariano a proceder "en julio de 1999, la ratificación de 9 de los 14 programas sociales de la Agenda Venezuela, instrumentados por el gobierno de Rafael Caldera (1993-1998), programas de carácter básicamente compensatorio-asistencial" (Maingón, 2004: 56). Se trata pues de dar continuidad a una política pública con fuertes influencias neoliberales. No se logran en esta primera etapa transformaciones estructurales en la manera de plantear el bienestar y el cuidado en la acción pública del país. Esto trae como consecuencia la dificultad para obtener resultados positivos en la mejora de la calidad de vida de la población.

En 2003, en un contexto marcado por los intereses electorales que provoca el complicado escenario que se le plantea al gobierno con el referéndum revocatorio, así como también por un aumento acelerado de la renta de origen petrolero, se inaugura una nueva etapa de la agenda social caracterizada por el desarrollo de las "misiones", programas sociales implementados con importantes grados de "para" y hasta lábil ins-

${ }^{13}$ Con la reforma constitucional de 2007 se va hacia un modelo más decididamente socialista de la economía y, aunque ésta no llega a aprobarse, la orientación se fortalece. Por ejemplo, se amplía el papel del Estado como propietario de medios de producción. 
titucionalidad ${ }^{14}$. Así pues, tales esfuerzos "estaban concebidos como una plataforma operativa que habría de garantizar, con un bajo grado de institucionalización, un rápido abastecimiento de sectores necesitados de la población (...). Frente a las tradicionales políticas sociales, se distinguen especialmente por su carácter extra-institucional" (Burchardt, 2009: 86). Con estos programas se ponía énfasis en la necesidad de llegar donde no lo hacían las instancias tradicionales oficiales, así como desburocratizar la política y promover la participación ciudadana. En tan solo dos años se logra implementar 13 misiones en áreas como la inclusión social, la educación, la salud, la alimentación y el hábitat, que alcanzan coberturas importantes en los sectores populares. Así, "aproximadamente un 30\% de la población (7.2 millones) en la Misión Barrio Adentro y un $53 \%$ en la Misión Mercal (12 millones)"15.

Cabe decir que a partir de 2006 y 2007 se detecta un debilitamiento de algunas misiones y una reducción de su cobertura. De manera paralela, se diversifica el foco de atención de las mismas y aparecen nuevos programas: unas primeras misiones dirigidas a poblaciones específicas y de carácter asistencial, como Misión Negra Hipólita, Misión Madres del Barrio, Misión José Gregorio Hernández y Misión Niño Jesús; unas segundas para el impulso del proyecto socialista, como Misión Che Guevara o Misión Villanueva (D’Elia y Quiroz, 2010). Durante el último periodo de la vida de Chávez, éste comienza a ejecutar medidas de centralización de la administración pública, y por ende de las misiones, con el objetivo de relanzar el proyecto nacional, y la calidad en el diseño e implementación de las políticas públicas, y en concreto de la política social. Y a partir del discurso del entonces presidente en la victoria electoral del 8 de octubre de 2012 se empieza a hablar de buscar la eficacia de las políticas y los servicios públicos.

De modo resumido, cuatro han sido las características que pueden destacarse del Régimen de Bienestar venezolano, centrado desde 2003 en el proyecto de las misiones: 1) La construcción de una nueva institucionalidad para la implementación de políticas sociales, que funciona paralela o yuxtapuesta a la acción de instituciones estatales oficiales. En un primer momento esta realidad acompañó un crecimiento importante en coberturas y gasto de las políticas sociales. Debe tenerse en cuenta la inoperancia de la administración pública tradicional del país, así como también las necesidades inmediatas a cubrir. De todas formas, la falta de canalización por vías institucionales provocó inestabilidad, fragmentación y focalización de las intervenciones sociales. También se han apuntado problemas de calidad, tendencia que en el último año se ha intentado corregir. 2) Existe poca incidencia del sistema de planificación nacional, a pesar de la

${ }^{14}$ Para un análisis detallado de la nueva institucionalidad/estatalidad involucrada en las misiones véase Otálvaro (2013: 109-115).

15 D’Elia y Quiroz (2010) citando a D’Elia y Maingón (2010). Pueden verse datos sobre las coberturas de las distintas misiones durante los años de apogeo de estos programas sociales en ambas obras. 
existencia de algunos documentos formales de programación de la acción estatal ${ }^{16} .3$ ) Énfasis en lo comunitario y políticas sociales centradas en las clases populares y escasa o nula acción que suponga encuentros inter-clases. La política social venezolana asume la corresponsabilidad del Estado y la comunidad en la prestación de los servicios. Eso hace partícipe a la ciudadanía no solo de la decisión sino también de la ejecución de la acción pública. En algunos casos esta característica ha derivado en falta de profesionalización de los servicios y en "feminización" del trabajo voluntario. 4) La centralidad de los recursos provenientes de la explotación del petróleo. Venezuela es un país rico en recursos naturales. El sistema impositivo queda en un segundo plano en el modelo de construcción y sostenibilidad del bienestar.

\subsubsection{Bolivia: la centralidad de la plurinacionalidad y el continuismo neoliberal en el campo del bienestar}

En Bolivia, a partir de la victoria de Evo Morales (2006), se empieza a experimentar un proceso de recuperación (o construcción) del Estado, de forma paralela al reconocimiento de la plurinacionalidad. De esta manera, se le da importancia al sistema de planificación, aunque de una forma menos completa que en Ecuador, resultando un Plan Nacional de Desarrollo con vigencia de 2006 a 2011 (a pesar de los intentos, no ha sido posible con posterioridad construir un nuevo plan). Distintos indicadores dan cuenta del aumento de la intervención del Estado en la economía y del retorno de ciertas funciones sociales a las instituciones públicas. Estas transformaciones, junto a un contexto económico favorable, dan lugar a mejoras destacadas en indicadores socioeconómicos ${ }^{17}$.

En el ámbito económico la clave del proceso boliviano también se hallará en las nacionalizaciones. En primer lugar la nacionalización de las empresas "capitalizadas"18, especialmente aquellas dedicadas a los hidrocarburos, y hubo intentos de renacionalizar el sector minero. A diferencia de las nacionalizaciones de los años 50 y 60 , las actuales se han basado en la compra del paquete de acciones en fideicomiso en las Administradoras de Fondos de Pensiones (AFP) con el objetivo de que el Estado asuma el control en el directorio de las empresas (Grebe López, 2009: 145). Estas operaciones se acompañaron de la renegociación de impuestos, regalías y precios de referencia de los contratos con las empresas petroleras, en cumplimiento de la nueva Ley de Hidrocarburos aprobada en

${ }^{16}$ En este sentido pueden considerarse Programa Económico de Transición 1999-2000 (1999), Líneas Generales del Plan de Desarrollo Económico y Social de la Nación (2001-2007) (2001) y el Proyecto Nacional Simón Bolívar. Primer Plan Socialista (PPS) Desarrollo Económico y Social de la Nación 2007-2013 (2007).

${ }^{17}$ Como dato destacable, en 2008 Bolivia fue declarado el tercer país en América Latina libre de analfabetismo, pasando de una tasa del $11 \%$ en 2005 al 3,4\% en 2008.

${ }^{18}$ Las empresas "capitalizadas" suponen la asociación estratégica entre el Estado y las compañías transnacionales, denominada "capitalización" en sectores como hidrocarburos, energía eléctrica, telecomunicaciones, ferrocarriles y transporte aéreo. 
2005. Los efectos han sido contundentes en términos de aumento de los ingresos fiscales y de la recaudación tributaria, lo cual no ha estado exento de conflictos ligados a las renegociaciones y batallas judiciales en tribunales internacionales ${ }^{19}$. Este excedente se utilizó para diseñar e implementar políticas sociales diversas tales como: Renta Dignidad para la tercera edad, Bono Juancito Pinto para niños en edad escolar y Bono Madre Niño-Niña "Juana Azurduy" para mujeres embarazadas y niños menores de 2 años.

Es importante indicar, según lo sostienen algunos autores, que una de las mayores dificultades de esta reconstrucción de la capacidad estatal ha sido la ausencia o déficit de una elite intelectual capaz de proponer a la sociedad un panorama estratégico en sintonía con las nuevas condiciones nacionales e internacionales: "La constelación de poder emergente de las consultas populares le ha permitido al MAS proceder a una sustitución masiva del personal del Estado. Este nuevo personal ya no proviene principalmente de las capas medias urbanas, que disponían de algún tipo de preparación para el ejercicio de funciones y competencias en la administración pública" (Grebe López, 2009: 149).

En relación al campo social la intervención se amplía en cuanto a inversión/gasto social y coberturas, y se actúa dando un espacio importante a la cuestión de la plurinacionalidad e interculturalidad. Sin embargo, el esquema de actuación sigue marcado por las transferencias monetarias condicionadas ${ }^{20}$, la ejecución de programas focalizados ${ }^{21}$, y un pronunciado peso de la presencia de ONGs y organismos internacionales de cooperación. Aunque con mejorías evidentes en el periodo estudiado, la fuerte presencia de pobreza y necesidades insatisfechas en el país así como la falta de una administración pública estable y consolidada, son algunos de los motivos que pueden esgrimirse para explicar la continuidad conceptual y operativa en la agenda social. Así pues, y citando a fuentes gubernamentales, "las principales medidas implementadas (...) fueron el descongelamiento del Salario Mínimo Nacional (SMN), los continuos incrementos salariales por encima de

${ }^{19}$ En cuanto a los ingresos del sector público boliviano, se observa un aumento relativo importante de ingresos procedente de regalías mineras e impuesto sobre hidrocarburos. Teniendo en cuenta el índice de los ingresos consolidados del sector no financiera (ver Grebe López, 2009: 1946), y tomando el año 1997 como punto de partida, se alcanzan las siguientes cifras en 2007: ingresos totales pasa de 100 a 365,5; renta interna a 321,4; renta aduanera a 186,8; regalías mineras a 929,6 e impuestos sobre hidrocarburos a 636,1 y otros ingresos a 356,7 .

${ }^{20}$ En 2012 tres de cada diez bolivianos se benefician de las transferencias monetarias condicionadas: Renta Dignidad - un pago de por vida no heredable, y destinado a todas la bolivianas y bolivianos que tengan 60 años-, Bono Juancito Pinto — establecido con el objetivo de incentivar la matriculación en los centros educativos y disminuir la inasistencia y la deserción escolar — y Bono "Juana Azurduy" - transferencia otorgada en beneficio de las madres en periodo de embarazo y niños y niñas menores de dos años-

${ }^{21}$ Entre otros el Programa "Bolivia Cambia, Evo Cumple", iniciado en 2006 y que tiene por objetivo destinar recursos directos a los municipios y comunidades (4.127 proyectos, 389 millones de dólares); el Programa Nacional de Post Alfabetización "Yo Sí Puedo Seguir" 2009; el Programa "más inversión para el agua" o la Tarifa Dignidad por bajo consumo de electricidad que beneficia al 50\% del total de consumidores de energía eléctrica. 
la tasa de inflación - con lo que se incrementa el salario real y la capacidad de compra de los trabajadores-, y la entrega de la Renta Dignidad, el Bono Juancito Pinto y el Bono Niño-Niña "Juana Azurduy" en favor de la población más vulnerable y que permitieron que miles de familias incrementen sus ingresos económicos y mejoren su calidad de vida" (Ministerio de Economía y Finanzas Públicas, 2013b: 154).

Debe señalarse un aumento importante del gasto social del gobierno nacional, que en 2012 llega al 11,5\% del PIB. Desde 2006 esta cifra corresponde a un incremento del 97\%, aumento parecido al que se experimenta en los otros países a los que hacemos referencia. De forma desagregada, el sector Educación representa el 45,7\% del gasto total, seguido por Protección Social con el 40,4\%, después el Sector Salud, el 11,7\% y Vivienda y Servicios Comunitarios con el 2,3\%. (Ministerio de Economía y Finanzas Públicas, $2013 \mathrm{~b}^{22}$ ). También debe destacarse una modesta extensión del sistema de pensiones vinculado a la seguridad social (contributiva y no contributiva) con la Ley 065, vigente desde diciembre de 2010.

En este sentido, se puede hablar de una universalización de mínimos de ciertos derechos de educación, salud y protección social. El aumento de gasto social y la existencia de unas determinadas prioridades políticas provocan un aumento de coberturas de servicios que efectivizan derechos sociales, así como también una destacable reducción de indicadores como el de pobreza moderada y extrema, y aquellos que hacen referencia a la desigualdad. En el tema de protecciones ligadas al trabajo, la gran proporción de un mercado informal hace que no se avance mucho en este sentido.

\section{A modo de conclusión. Entre la continuidad y el cambio}

La ampliación de la intervención social que llevan a cabo los tres casos analizados, así como los procesos de recuperación (o construcción) del Estado, y la preocupación por desarrollar políticas públicas que beneficien a las amplias mayorías sociales en la provisión de su bienestar, permiten pensar en una potencial transformación en las agendas sociales (ampliadas). Por el momento, los Regímenes de Bienestar en estos países se encuentran en una fase de construcción y contienda, y por lo tanto aún es pronto para poder caracterizarlos de manera exhaustiva. Dicho esto, podemos entrever que en los países descritos empezamos a encontrar elementos característicos no solo de los regímenes familiaristas sino también en aquellos estatal-productivistas y estatal-proteccionistas antes descritos. En este sentido y como se ha ido apuntando, las transformaciones estructurales acaecidas en toda la región pueden requerir la construcción de una nueva tipología a través de la cual clasificar los regímenes de bienestar en un periodo postneoliberal.

\footnotetext{
${ }^{22}$ Ver también CEPALSTAT. Base de datos y Publicaciones Estadísticas.
} 
A modo de resumen y cierre del texto, se adjunta un cuadro descriptivo, utilizando las herramientas analíticas de Adelantado/Gomà (2000), para visualizar de manera esquemática cómo se están conformando en cada país analizado los componentes constitutivos del régimen de bienestar. Este punto de partida será clave para pensar nuevas tipologías.

De esta manera se observa como a pesar de los avances en la forma de pensar el bienestar en estos países, se debe indicar que todavía hay un gran trabajo para hacer en la materialización de propuestas, derechos y servicios. Siendo conscientes de las transformaciones acaecidas y avances experimentados durante los últimos años, estamos en países con aún importantes índices de desigualdad y pobreza, unos mercados laborales predominantemente informales, con una fractura de género muy marcada, unas economías poco desarrolladas y dependientes del mercado internacional, y unos sistemas de financiación públicos que priorizan aún los recursos provenientes del extractivismo. Se requieren importantes políticas de transformación estructural de la matriz productiva, las estructuras administrativas, las intervenciones sociales y la cultura cívico-democrática. Y no solo se trata de una cuestión de grado, incremental, sino también estamos frente a un desafío de concepciones.

Así pues, y volviendo al terreno de las políticas de bienestar, a pesar de la retórica rupturista, estamos frente a políticas sociales en las que toman una gran centralidad las políticas de transferencias condicionadas y las medidas de lucha contra la pobreza, frente a políticas públicas de carácter universalista, con lógicas interclasistas y no solo hacia poblaciones en situaciones de pobreza o extrema pobreza, y de consolidación de sistemas públicos de salud y educación de calidad que puedan competir con el sector privado. Se detecta un primer peldaño de "desmercantilización" (Esping Andersen, 1993 y 2000) por la extensión de gasto público y coberturas en relación a estos servicios, esto es, de inversión en capital humano, pero aún se es débil en un segundo peldaño: la calidad y la universalidad. Esto último todavía es débil, y solo parecen existir algunas señales importantes de cambio en el caso ecuatoriano.

Se detecta también una profunda desconexión entre el campo de políticas sociales en sentido estricto y las laborales y tributarias (con algunas salvedades). Es un reto repensar las políticas de bienestar y protección en su vinculación con el mercado de trabajo, y la sostenibilidad y financiamiento que este puede proveer a tales acciones. Esto implica desarrollar acciones de mercantilización de la fuerza de trabajo, revelando que el mercado laboral tiene capacidad real para proveer de trabajo remunerado, así como calidad de dicho trabajo según estabilidad, protección social y otras garantías laborales (Martínez Franzoni, 2007: 11). Es decir, formalización del mercado laboral y consecuentemente altos niveles de seguridad social vinculados a esta inserción. Es también importante tener en cuenta otros elementos tales como los actores políticos involucrados en tales articulaciones; no ya beneficiarios de transferencias monetarias condicionadas sino, por ejemplo, trabajadores, sindicatos, patronales, etc. 


\section{Tabla 4: Componentes del Bienestar en Ecuador (2007-2012), Venezuela (1998-2012) y Bolivia (2006-2012)}

\begin{tabular}{|c|c|c|c|}
\hline $\begin{array}{l}\text { Dimensiones del } \\
\text { bienestar }\end{array}$ & Ecuador & Venezuela & Bolivia \\
\hline $\begin{array}{l}\text { Referente normativo } \\
\text { global del modelo }\end{array}$ & $\begin{array}{l}\text { Discursivamente universalista } \\
\text { en la carta magna, el Plan } \\
\text { Nacional del Buen Vivir y } \\
\text { otros documentos oficiales }\end{array}$ & $\begin{array}{l}\text { Discursivamente } \\
\text { universalista en la Carta } \\
\text { Magna. Focalización como } \\
\text { fundamento de las "misiones" }\end{array}$ & $\begin{array}{l}\text { Discursivamente universalista. } \\
\text { Simbólicamente } \\
\text { importante la cuestión de la } \\
\text { plurinacionalidad }\end{array}$ \\
\hline $\begin{array}{l}\text { Manera como se } \\
\text { configuran los derechos } \\
\text { sociales pilares del } \\
\text { bienestar (salud y } \\
\text { educación) }\end{array}$ & $\begin{array}{l}\text { Universalización de servicio } \\
\text { público en base a derechos. } \\
\text { Todavía importante } \\
\text { diferenciación en las calidades } \\
\text { entre público y privado*. }\end{array}$ & $\begin{array}{l}\text { Políticas destinadas a sectores } \\
\text { socioeconómicamente pobres }\end{array}$ & $\begin{array}{l}\text { Universalización de mínimos. } \\
\text { Problemas aún de coberturas } \\
\text { universales, sobretodo en } \\
\text { salud y educación secundaria } \\
\text { y superior }\end{array}$ \\
\hline $\begin{array}{l}\text { Modo de estructurar la } \\
\text { protección social }\end{array}$ & $\begin{array}{l}\text { Discursivamente con } \\
\text { una concepción amplia y } \\
\text { progresista de la protección } \\
\text { social. } \\
\text { Aumento de políticas de } \\
\text { atención a la dependencia, aún } \\
\text { con claro sesgo familiarista. } \\
\text { Aumento de las políticas } \\
\text { de inclusión social, aún } \\
\text { herederas de perspectivas } \\
\text { propias de la etapa neoliberal } \\
\text { (asistencialistas, con } \\
\text { comprobación de medios de } \\
\text { vida, etc.). } \\
\text { Continúan de manera } \\
\text { importante las políticas de } \\
\text { transferencias condicionadas } \\
\text { de renta (Ej. BDH). } \\
\text { Sistema de seguridad } \\
\text { social con ampliación de } \\
\text { cobertura pero pendiente } \\
\text { de reforma (esquema de } \\
\text { cobertura reducida, altamente } \\
\text { fragmentado, corporativizado } \\
\text { y regresivo) }\end{array}$ & $\begin{array}{l}\text { Las políticas de atención a la } \\
\text { dependencia y las de inclusión } \\
\text { social se realizan a través de } \\
\text { "misiones". } \\
\text { La seguridad social no llega a } \\
\text { los clases populares y medias } \\
\text { bajas. }\end{array}$ & $\begin{array}{l}\text { Discursivamente con } \\
\text { una concepción amplia y } \\
\text { progresista de la protección } \\
\text { social pero aún con la } \\
\text { familia -y la mujer como } \\
\text { cuidadora- en el centro. } \\
\text { Continúan de manera } \\
\text { importante las políticas de } \\
\text { transferencias condicionadas } \\
\text { de renta (ex. Renta Dignidad, } \\
\text { Bono Juancito Pinto, Bono } \\
\text { Madre Niño-Niña "Juan } \\
\text { Azurduy) } \\
\text { Universalización de mínimos } \\
\text { de algunas prestaciones } \\
\text { de la seguridad social } \\
\text { (jubilaciones). }\end{array}$ \\
\hline Régimen de fiscalidad** & $\begin{array}{l}\text { Aumentan los recursos } \\
\text { públicos y la eficacia y } \\
\text { eficiencia del sistema } \\
\text { tributario*** } \\
\text { Avances en la progresividad } \\
\text { tributaria. }\end{array}$ & $\begin{array}{l}\text { Aumento de recursos } \\
\text { públicos (principalmente por } \\
\text { nacionalizaciones y regalías). } \\
\text { Los ingresos de las } \\
\text { "misiones" provienen } \\
\text { mayoritariamente de las rentas } \\
\text { petroleras, no hay conexión } \\
\text { con la reforma del sistema } \\
\text { tributario como mecanismo de } \\
\text { financiamiento (y, por ende, } \\
\text { de re-distribución del ingreso) }\end{array}$ & $\begin{array}{l}\text { Aumento de recursos } \\
\text { públicos (principalmente por } \\
\text { nacionalizaciones y regalías). } \\
\text { Se introducen algunas } \\
\text { reformas tributarias pero } \\
\text { aún débiles para construir } \\
\text { un sistema progresivo y } \\
\text { que financie el modelo de } \\
\text { bienestar y cuidado }\end{array}$ \\
\hline
\end{tabular}




\begin{tabular}{|c|c|c|c|}
\hline $\begin{array}{l}\text { Dimensiones del } \\
\text { bienestar }\end{array}$ & Ecuador & Venezuela & Bolivia \\
\hline $\begin{array}{l}\text { Relaciones de } \\
\text { empleo***** }^{*}\end{array}$ & $\begin{array}{l}\text { Avance en la dignificación del } \\
\text { trabajador, con modificaciones } \\
\text { legislativas y políticas } \\
\text { públicas novedosas } \\
\text { Mejoras en indicadores como } \\
\text { trabajo pleno y afiliados a la } \\
\text { seguridad social. } \\
\text { Sin embargo todavía la } \\
\text { estructura del mercado laboral } \\
\text { tiene una alta presencia de } \\
\text { informalidad }\end{array}$ & $\begin{array}{l}\text { Si bien se registran acciones } \\
\text { en la dignificación del } \\
\text { trabajador y aumentos en } \\
\text { la protección del trabajador } \\
\text { frente al empresario se trata } \\
\text { de avances modestos en } \\
\text { la provisión de bienestar } \\
\text { vía políticas laborales y de } \\
\text { protección laboral. }\end{array}$ & $\begin{array}{l}\text { Avance en la dignificación } \\
\text { del trabajador (incrementa el } \\
\text { salario real y la capacidad de } \\
\text { compra de los trabajadores). } \\
\text { Todavía se trata de avances } \\
\text { modestos en la provisión } \\
\text { de bienestar vía políticas } \\
\text { laborales y de protección } \\
\text { laboral. }\end{array}$ \\
\hline $\begin{array}{l}\text { Efectos en la estructura } \\
\text { social }\end{array}$ & $\begin{array}{l}\text { Mejora indicadores } \\
\text { macroeconómicos como } \\
\text { pobreza, indigencia y } \\
\text { desigualdad. } \\
\text { Falta trabajar un más en } \\
\text { esquemas menos estratificados } \\
\text { de bienestar. }\end{array}$ & $\begin{array}{l}\text { Mejora indicadores } \\
\text { macroeconómicos como } \\
\text { pobreza, indigencia y } \\
\text { desigualdad. } \\
\text { Esquemas altamente } \\
\text { estratificados de bienestar. }\end{array}$ & $\begin{array}{l}\text { Mejora indicadores } \\
\text { macroeconómicos como } \\
\text { pobreza, indigencia y } \\
\text { desigualdad. } \\
\text { Esquemas altamente } \\
\text { estratificados de bienestar. }\end{array}$ \\
\hline
\end{tabular}

\begin{abstract}
Notas:
* Ver en ENEMDU-INEC de junio 2011 (datos instituto oficial de estadística de Ecuador) la diversa valoración del sector público y el sector privado a partir de diversas expresiones. Aunque la tendencia es a la mejora si comparamos con datos de septiembre de 2008 , la diferencia entre ambos aún es destacada. Por ejemplo: innovación (un $42,6 \%$ cree que es mejor en el sector público y un 55,3\% en privado); mejores profesionales (un $40,6 \%$ cree que es mejor en el sector público y un $59,4 \%$ en privado); calidad del servicio (un $38,2 \%$ cree que es mejor en el sector público y un $61,4 \%$ en privado); etc.

** Ver en la Tabla 1 los indicadores "Ingresos del gobierno central como porcentaje del PIB" y "Gastos del gobierno central como porcentaje del PIB", para los países de Ecuador y Venezuela (de Bolivia no se han encontrado los datos). Para el caso de Ecuador el crecimiento de ambos indicadores es muy acosado, de 2005 a 2012. Para el caso de Venezuela, existe un crecimiento en el período 1997-2005 pero un decrecimiento en el período 2005-2012 para el indicador de ingreso. Esta modificación puede estar indicándonos la precariedad en la consolidación de ingresos estatales que supone la dependencia del precio de las materias primas, y no de un sistema tributario sólido, eficiente y progresivo.

*** La recaudación tributaria en relación al PIB aumenta de manera destacada en Ecuador en los últimos años. Así pues, en 2006 era de un $10 \%$ y en 2011 de un 12,3 según datos del Plan Nacional del Buen Vivir 2013-2017 (pg. 115).

**** Ver en Tabla 1 los indicadores "Tasa desempleo" y "Ocupados urbanos en el sector informal del mercado de trabajo". Ambos han experimentado mejoras en los tres países, pero aún no estamos en disposición de hablar de mercados de trabajo de calidad. Cabe reconocer, pero, que las políticas implementadas a nivel laboral y productivo, junto con un contexto macroeconómico favorable, están yendo por buen camino. ***** Eliminación de la tercerización, penalización de la no afiliación por parte del empresario, afiliación obligatoria para el trabajo doméstico, y mejoras laborales en el sector público.

****** Ver en Tabla 1 los indicadores "Pobreza", "Indigencia" y "Gini". Se puede comprobar que en los tres países mejoran de manera muy importante la pobreza y la desigualdad. Esto se debe no solo al desarrollo de políticas sociales (perspectiva micro) de mejora de la situación de aquellas personas con dificultad sino también de adopción de políticas macroeconómicas y productivas (perspectiva macro) que cambian en modelo de país.
\end{abstract}

Fuente: Elaboración propia a partir de las dimensiones elaboradas por Adelantado y Gomà (2000:69).

En el reto de la financiación de los Estados aún se arrastran herencias del pasado neoliberal y rentista-extractivista. No existe una consolidación destacable del sistema tributario - salvo parcialmente en el Ecuador - ni una conexión de este con cambios en la matriz productiva que permitan presupuestos públicos más autónomos, con capacidad redistributiva y mayor sostenibilidad en el tiempo respecto a la inversión social. Todo esto sin duda está atado a las capacidades estatales de regulación y planificación y a una idónea y eficiente burocracia pública. Debe trabajarse por conseguir una mejor administración tributaria y una mejor administración. 
En referencia a la (des)familiarización (Martínez Franzoni, 2007) del bienestar en estos tres países, debe tenerse en cuenta la disponibilidad de trabajo femenino no remunerado basado en la división sexual del trabajo, es decir, la participación del ámbito doméstico en la garantía del bienestar y la protección. En esta dimensión hay escasos avances en los tres $\operatorname{casos}^{23}$. No se rompe la importante fractura de género que opera en estos países en la esfera productiva y reproductiva, que genera importantes desigualdades en el acceso a recursos simbólicos y materiales, así como tampoco se detectan políticas públicas en la erosión de esta brecha.

En definitiva y para concluir, los avances producidos en el campo social, y de manera más modesta en el laboral y tributario, vinculados a una recuperación por parte de los poderes públicos de las funciones sociales y de rectoría de la economía, y de una (re)construcción de la administración pública y consolidación de la capacidad de planificar, estarían introduciendo un cuestionamiento de la tipología establecida por Martínez Franzoni (2007) a partir de un análisis de la situación en plena etapa neoliberal. Y no solo en cambios que podrían estar detectándose $\mathrm{e}^{24}$ dentro de la tipología, sino sobre todo en la discusión de la propia clasificación. Merece, pues, que futuros estudios trabajen en la construcción de una nueva tipología del bienestar en América Latina. Existen intensas dinámicas a la vez de continuidad y cambio en los tres países analizados, y creemos que estas son extensivas en una buena parte de países de América Latina a partir de los años 2000, que nos hacer pensar en la necesidad de ir más allá de la interesante tipología que mapeó los países latinoamericanos en la era neoliberal, dividiéndolos en estatal-productivistas, estatal-proteccionistas y familiaristas.

${ }^{23}$ Teniendo en cuenta la esfera productiva puede verse la importancia de la desprotección del trabajo doméstico (llevado cabo centralmente por mujeres que desarrollan estas labores de forma paralela a la labor no reconocida, regulada y remunerada en sus hogares). Así pues, de las personas que se dedican al servicio doméstico en Bolivia solo un 1,1\% esta afiliada a un sistema de pensiones y un 15,5\% al de salud en 2009; en Ecuador un 38,7\% y un 46,8\% en 2011; y en Venezuela un 18,7\% al de pensiones (CEPAL, 2013: 22).

${ }^{24}$ Utilizando el esquema de Martínez Franzoni (2007) podría decirse que Ecuador es el país que más camina hacia un esquema estatal-productivista, seguido por Venezuela. Bolivia pese a que ha dado señales de querer romper la lógica del esquema familiarista todavía no logra encaminarse de manera certera hacia otra categoría. 


\section{Bibliografía}

Adelantado, J. y R. Gomì (2000): "El contexto: la reestructuración de los regímenes de bienestar europeos", en José Adelantado (coord.), Cambios en el Estado de Bienestar, Barcelona, Icaria, pp. 63-96.

Barba, C. (2005): "Paradigmas y Regímenes de Bienestar", Cuaderno de Ciencias Sociales 137, FLACSO-Costa Rica.

Burchard, H.J. (2009): “Un misionero y sus misiones. Progresos y trabas de la nueva política social en Venezuela", Revista Politeia, 42, 79-96.

Comisión Económica para América Latina y el Caribe (CEPAL) (2013): Panorama Social de América Latina 2013, Santiago de Chile, ONU.

D’Elia, Y. y C. Quiroz (2010): Las Misiones Sociales: ¿Una Alternativa para Supera la Pobreza?, Caracas, ILDIS.

D’Elia, Y. y T. Maingon (2010): "Balance de lo Social en las Prácticas del Gobierno Bolivariano", en Fracesca Ramos Pistamaro, et al. (eds.), Hugo Chávez: una década en el poder, Colombia, CEPI-OV y Universidad del Rosario, pp.365-385.

DÉNIZ, J. A. (2006), "Crecimiento, inseguridad económica y nueva ciudadanía con equidad", en Antonio Santamaría (ed.), América Latina, crecimiento económico sostenido y equidad en perspectiva histórica, Madrid, Instituto de Cultura-Fundación MAFRE, pp. 105-118.

Esping-Andersen, G. (1993): Los tres mundos del Estado del Bienestar, València, Alfons el Magnànim.

Esping-Andersen, G. (2000): Fundamentos sociales de las economías postindustriales, Barcelona, Ariel.

FALCONÍ, F. y P. MuÑoz (2012): "Ecuador: de la receta del "Consenso de Whashington" al posneoliberalismo", en Sebastian Mantilla y Santiago Mejía (eds.), Rafael Correa. Balance de la Revolución Ciudadana, Quito, Planeta, pp. 75-76.

FilgueirA, F. (1998): "El nuevo modelo de prestaciones sociales en América Latina: eficiencia, residualismo y ciudadanía estratificada", en Brian Roberts (ed.), Ciudadanía y Política Social, San José, FLACSO/SSRC, pp. 71-116.

Gallego, R., R. Gomì y J. Subirats (2003): "Las dinámicas de cambio en las políticas sociales: España en perspectiva comparada", en Raquel Gallego, Ricard Gomà y Joan Subirats (coords.), Estado de bienestar y comunidades autónomas: la descentralización de las políticas sociales en España, Madrid, Tecnos, 46-68.

Guerra, J.A. (2009): Caracterización de la Política Económica en el Modelo EstadoGobierno venezolano, Caracas, Ildis.

Grebe, H. (2009): "Estado y mercado en Bolivia: una relación pendular", Nueva Sociedad, 221, pp.137-150. 
MaInGón, T. (2004): "Política social en Venezuela: 1999-2003", Cuadernos del CENDES, 21 (55), pp. 47-73.

MAInGón, T. (2006): "El estado de bienestar en Venezuela: el caso de las misiones sociales", Ágora-Revista de Ciencias Sociales, 14, pp. 31-71.

MAingón, T. (coord.) (2006): Balance y perspectivas de la política social en Venezuela, Caracas, ILDIS.

Martínez, J. (2007): Regímenes de bienestar en América Latina, Madrid, Fundación Carolina.

MartínezDalmau,R.(2008): "Supremacía de la Constitución, control de la constitucionalidad y reforma constitucional”, en Ramiro Ávila, Agustín Grijalva y Rubén Martínez (eds.), Desafíos constitucionales. La Constitución ecuatoriana de 2008 en perspectiva, Quito, Ministerio de Justicia y Derechos Humanos - Tribunal Constitucional, pp. 279-291.

Mateo Tome, J.P. y E. Sanchez Iglesias (2010), "Política económica en Venezuela: propósitos, mediadas y resultados obtenidos en la última década", XIV Encuentro de Latinoamericanistas Españoles, Santiago de Compostela, Consejo Español de Estudios Iberoamericanos (CEEIB), pp. 2898-2931.

Mesa-Lago, C. (1991): "Social Security and Prospects for Equity in Latin America", Discussion Paper 140, Washington D.C, Banco Mundial.

Ministerio de Planificación del Desarrollo (2006): Plan Nacional de Desarrollo "Bolivia digna, soberana, productiva y democrática para vivir bien". Lineamientos estratégicos 2006-2011, La Paz, Gaceta Oficial de Bolivia.

Ministerio de Economía y Finanzas Públicas (2013): Bolivia, Logros del nuevo modelo económico, La Paz, Ministerio de Economía y Finanzas Públicas.

Ministerio de Economía y Finanzas Públicas (2013b): Memoria de la economía boliviana, La Paz, Ministerio de Economía y Finanzas Públicas.

Ministerio del Poder Popular para la Planificación y el Desarrollo (MPD) (1999): Programa Económico de Transición 1999-2000, Caracas.

Ministerio del Poder Popular para la Planificación y el Desarrollo (MPD) (2001): Líneas Generales del Plan de Desarrollo Económico y Social de la Nación (20012007), Caracas.

Ministerio del Poder Popular para la Planificación y el Desarrollo (MPD) (2007): Proyecto Nacional Simón Bolívar. Primer Plan Socialista (PPS) Desarrollo Económico y Social de la Nación 2007-2013, Caracas.

Minteguiaga, A. (2012): "Política y Políticas Sociales en el Ecuador Reciente: dificultades asociadas a la salida del ciclo neoliberal", Revista de Ciencias Sociales de la Universidad de Costa Rica, 135-136, pp. 45-58. 
Minteguiaga, A. y G. Ubasart-González (2013a): "Régimen de Bienestar y procesos de transformación en América Latina. El caso del Ecuador", ponencia presentada en el IV Congreso del Grupo de Investigación en Gobierno, Administración y Políticas Públicas (GIGAPP), INAP-España.

Minteguiaga, A. y G. Ubasart-GonzÁlez (2013b): Revolución Ciudadana y Régimen de Bienestar en el Ecuador (2007-2012), Informe final de la investigación, Buenos Aires, CLACSO.

MuÑoz, P. (ed.) (2014): Construcción de un Estado democrático para el Buen Vivir: Análisis de las principales transformaciones del Estado ecuatoriano (2007-2012), Quito, SENPLADES.

OrLoff, A.S. (1993): "Gender and the social rights of citizenship: The comparative analysis of gender relations and welfare states", American Sociological Review, 58, pp 303-328.

OtÁlvaro, A. (2013): "Misiones Bolivarianas. Transformaciones sociales y limitantes estructurales en la Venezuela del siglo XXI", Revista Estado y Comunes, Quito, IAEN, pp. 98-124.

Palazuelos, A. (2000), "Introducción a la realidad económica latinoamericana”, en F. Harto de Vera (comp.), América latina: desarrollo, democracia y globalización, Madrid, Trama, Centro de Estudios y Cooperación para América Latina, pp. 25-54.

Polanyi, K. (1957): The Great Transformation. The Political and Economics Origins of our Time, Boston, Beacon Press.

Ramírez, F. (2006): "Mucho más que dos izquierdas", Nueva Sociedad, 205, pp. 30-44.

Ramírez, F. (2012a): "Crisis neoliberal y reconfiguraciones estatales: Ecuador y la heterodoxia sudamericana”, Linea Sur, 2, pp. 84-113.

RamíreZ, F. (2012b): "Reconfiguraciones estatales en Ecuador: 1990-2011”, en Mabel Thwaites Rey, El Estado en América Latina: continuidades y rupturas, Santiago de Chile, Arcis-CLACSO, pp. 341-374.

Ramírez, F. y A. Minteguiaga (2007): "El nuevo tiempo del Estado. La política posneoliberal del correísmo", Observatorio Social de América Latina (OSAL), 22, pp. 87-103.

Rossanvallon, P. (1981): La crise de l'Etat-providence, Paris, Éditions du Seuil.

Secretaría Nacional de Planificación y Desarrollo (SenPladeS) (2007): Plan Nacional de Desarrollo (2007-2010), Quito.

Secretaría Nacional de Planificación y Desarrollo (SENPladeS) (2009): Plan Nacional para el Buen Vivir (2009-2013), Quito.

Secretaría Nacional de Planificación y Desarrollo (SENPladeS) (2013): Plan Nacional para el Buen Vivir (2013-2017), Quito.

SPICKer, P. (1988): Principles of Social Wealfare. An introduction to thinking about the Wealfare State, New York, Roudledge. 
Stefanoni, P. (2011): "Estado de la democracia en Venezuela, Bolivia y Ecuador", Observatorio Social de América Latina (OSAL), 30, pp.79-110.

Titmuss, R. (1958): Essay of the Welfare State, Londres, Allen and Unwin.

Viciano, R. y R. Martínez (2010): "Aspectos generales del nuevo constitucionalismo Latinoamericano", en VV.AA., El nuevo constitucionalismo en América Latina, Quito, Corte Constitucional, pp.9-42. 